\title{
Rapid lipid enrichment in $\omega 3$ fatty acids: Plasma data
}

\author{
YVON A. CARPENTIER, SEBASTIEN PELTIER, LAURENCE PORTOIS, \\ ABDULLAH SENER and WILLY J. MALAISSE \\ Laboratories of Experimental Hormonology and Surgery, Brussels Free University, Brussels, Belgium
}

Received November 7, 2007; Accepted December 11, 2007

\begin{abstract}
The bolus intravenous injection of a novel mediumchain triglyceride:fish oil emulsion to normal subjects was recently reported to enrich within 60 min the phospholipid content of leucocytes and platelets in long-chain polyunsaturated $\omega 3$ fatty acids. The present study, conducted in second generation $\omega 3$-depleted rats, aimed at investigating whether such a procedure may also increase within $60 \mathrm{~min}$ the phospholipid content of $\omega 3$ fatty acids in cells located outwards the bloodstream, in this case liver cells, and whether this coincides with correction of the perturbation in the liver triglyceride fatty acid content and profile otherwise prevailing in these rats. This first report deals mainly with the fatty acid pattern of plasma lipids in male $\omega 3$-depleted rats that were non-injected or injected with either the $\omega 3$-rich emulsion or a control medium-chain triglyceride:olive oil emulsion. The results provide information on the fate of the exogenous lipids present in the lipid emulsions and injected intravenously $60 \mathrm{~min}$ before sacrifice. Moreover, in the uninjected $\omega 3$-depleted rats the comparison between individual plasma and liver measurements indicated positive correlations in the fatty acid profile of phospholipids and triglycerides.
\end{abstract}

\section{Introduction}

The intravenous injection of a suitable emulsion rich in fish oil was recently proposed as a tool to increase rapidly the cell phospholipid content of long-chain polyunsaturated $\omega 3$ fatty acids and, hence, as a procedure to protect selected patients against the risk of undesirable events, e.g. cardiac arrhythmia following anesthesia and surgery (1). A first study conducted in normal volunteers indeed documented that the bolus intravenous injection of $50 \mathrm{ml}$ of a novel $20 \%(\mathrm{w} / \mathrm{v})$ medium-chain triglyceride:fish oil emulsion caused within 60 min a marked

Correspondence to: Professor W.J. Malaisse, Laboratory of Experimental Hormonology, Brussels Free University, 808 Route de Lennik, B-1070 Brussels, Belgium

E-mail: malaisse@ulb.ac.be

Key words: second generation rats depleted in long-chain polyunsaturated $\omega 3$ fatty acids, plasma and liver lipid fatty acid profile, medium-chain triglyceride:fish oil emulsion increase of the phospholipid weight percentage of $\omega 3$ fatty acids in both circulating leucocytes and platelets (2).

The major aims of the present study were to investigate: i) whether the intravenous injection of the same emulsion to second generation rats depleted in $\omega 3$ fatty acids may also increase within $60 \mathrm{~min}$ the phospholipid content of $\omega 3$ fatty acids in cells located outside the bloodstream, in this case liver cells, and ii) whether, under these experimental conditions, the enrichment of liver phospholipids in $\omega 3$ fatty acids coincides with a correction of the perturbation of the content and fatty acid pattern of liver triglycerides otherwise prevailing in these second generation w3-depleted animals.

This first report deals mainly with the fatty acid pattern of plasma phospholipids, triglycerides, diglycerides and unesterified fatty acids in male $\omega 3$-depleted rats that were non-injected or injected with either the $\omega 3$-rich emulsion or a control medium-chain triglyceride:olive oil emulsion.

\section{Materials and methods}

Eighteen male and five female second generation rats depleted in long-chain polyunsaturated $\omega 3$ fatty acids ( $\omega 3$-depleted rats) were given free access to food and tap water up to the time of anesthesia. The procedure used to prepare second generation w3-depleted rats and the diet offered to these rats were defined in a prior report (3). Some of these rats were injected intravenously $60 \mathrm{~min}$ before sacrifice with $1.0 \mathrm{ml}$ of either an $\omega 3$ fatty acid-rich medium-chain triglyceride:fish oil emulsion (MCT:FO) or a control $\omega 3$ fatty acid-poor medium-chain triglyceride:olive oil emulsion (MCT:OO) (3). The lipid composition of these emulsions, as assessed by the same procedure of that used for the measurements of plasma and liver lipids (4), is documented in Table I. The MCT:OO and MCT:FO emulsions were provided, respectively, by B. Braun (Melsungen, Germany) and Laboratorios Grifols (Barcelona, Spain).

The animals were anesthetized with pentobarbital $(60 \mathrm{mg}$ i.p.; Nembutal, Cava, Brussels, Belgium) prior to the intravenous injection in the saphenous vein of the lipid emulsions $(1.0 \mathrm{ml})$ and maintained under anesthesia during the ensuing $60 \mathrm{~min}$ before sacrifice. The uninjected animals were also anesthetized before sacrifice.

The present experiments were carried out in accordance with the principles of the Animal Experimentation Ethics Committee of Brussels University Medical School. The uninjected rats (NI) and those injected with either the MCT:OO emulsion (OO) or MCT:FO emulsion (FO) are 
Table I. Fatty acid content and pattern of the MCT:OO and MCT:FO emulsion.

\begin{tabular}{|c|c|c|c|c|c|c|c|c|}
\hline \multirow[b]{2}{*}{ Emulsion } & \multicolumn{4}{|c|}{ MCT:OO } & \multicolumn{4}{|c|}{ MCT:FO } \\
\hline & PL & $\mathrm{TG}$ & DG & NEFA & PL & TG & DG & NEFA \\
\hline Total content (mg/ml) & 9.38 & 177.82 & 1.31 & 0.68 & 9.82 & 164.5 & 15.82 & 0.97 \\
\hline C6:0 $(\%)$ & 0.0 & 0.0 & 0.0 & 0.0 & 0.0 & 0.1 & 0.0 & 0.0 \\
\hline C8:0 (\%) & 0.7 & 45.5 & 28.2 & 16.7 & 0.2 & 51.0 & 12.8 & 14.5 \\
\hline C10:0 (\%) & 0.3 & 34.1 & 30.8 & 12.4 & 0.2 & 34.6 & 9.5 & 9.5 \\
\hline $\mathrm{C} 12: 0(\%)$ & 0.0 & 0.3 & 0.0 & 0.0 & 0.0 & 0.0 & 0.0 & 0.0 \\
\hline $\mathrm{C} 14: 0(\%)$ & 0.3 & 0.0 & 0.0 & 6.1 & 0.0 & 0.1 & 0.3 & 3.0 \\
\hline C16:0 (\%) & 32.3 & 0.9 & 0.0 & 17.0 & 28.4 & 0.5 & 1.8 & 9.5 \\
\hline 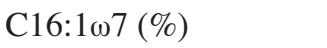 & 1.0 & 0.0 & 0.0 & 0.0 & 0.8 & 0.1 & 0.7 & 0.0 \\
\hline C18:0 (\%) & 11.3 & 0.7 & 0.0 & 8.0 & 11.1 & 0.4 & 1.8 & 4.5 \\
\hline 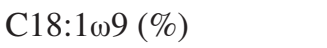 & 25.1 & 15.5 & 32.8 & 31.1 & 21.8 & 0.7 & 3.3 & 21.0 \\
\hline 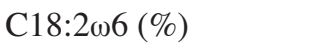 & 18.1 & 2.6 & 8.0 & 8.4 & 17.5 & 0.2 & 0.7 & 6.4 \\
\hline C20:0 (\%) & 0.0 & 0.0 & 0.0 & 0.0 & 0.0 & 0.1 & 0.4 & 0.0 \\
\hline C18:3w3 (\%) & 0.0 & 0.0 & 0.0 & 0.0 & 0.0 & 0.0 & 0.5 & 0.0 \\
\hline 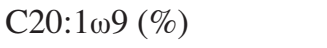 & 0.2 & 0.0 & 0.0 & 0.0 & 0.3 & 0.0 & 0.4 & 0.0 \\
\hline C18:4w3 (\%) & 0.0 & 0.0 & 0.0 & 0.0 & 0.0 & 0.2 & 1.0 & 0.0 \\
\hline 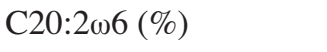 & 0.2 & 0.0 & 0.0 & 0.0 & 0.3 & 0.0 & 0.3 & 0.0 \\
\hline C20:3w6 (\%) & 0.3 & 0.1 & 0.0 & 0.0 & 0.0 & 0.0 & 0.0 & 0.0 \\
\hline C22:0 (\%) & 0.0 & 0.2 & 0.0 & 0.0 & 0.0 & 0.0 & 0.2 & 0.0 \\
\hline 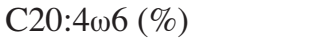 & 6.0 & 0.0 & 0.0 & 0.0 & 6.0 & 0.4 & 2.1 & 0.0 \\
\hline $\mathrm{C} 22: 1 \omega 9(\%)$ & 0.0 & 0.0 & 0.0 & 0.0 & 0.0 & 0.1 & 0.3 & 0.0 \\
\hline 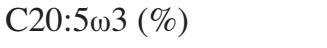 & 0.0 & 0.1 & 0.0 & 0.0 & 4.1 & 5.3 & 28.6 & 8.5 \\
\hline C24:0 (\%) & 0.0 & 0.0 & 0.0 & 0.0 & 0.0 & 0.0 & 0.1 & 0.0 \\
\hline 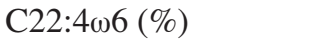 & 0.2 & 0.0 & 0.0 & 0.0 & 0.5 & 0.3 & 1.6 & 0.0 \\
\hline $\mathrm{C} 22: 5 \omega 3(\%)$ & 0.3 & 0.0 & 0.0 & 0.0 & 1.1 & 1.0 & 5.4 & 3.0 \\
\hline $\mathrm{C} 22: 6 \omega 3(\%)$ & 3.7 & 0.0 & 0.0 & 0.0 & 7.8 & 5.2 & 29.1 & 19.9 \\
\hline
\end{tabular}

PL, phospholipids; TG, triglycerides; DG, diglycerides; NEFA, non-esterified fatty acids.

preceded by the letter $\mathrm{M}$ (male) or $\mathrm{F}$ (female) according to the gender of the animals.

All results are expressed as the mean value ( \pm SEM), together with either the number of individual observations (n) or degree of freedom (d.f.). In certain instances, i.e. when the ratio between two variables yielded a high coefficient of variation, a geometric rather than arithmetic mean value was calculated. In such a case, the SEM given after the mean value corresponds to the mean of the upper and lower deviation from such a mean value (5). The statistical significance of differences between mean values was assessed by use of Student's t-test or, whenever so required, by variance analysis. The probability relative to correlation coefficients was calculated by assuming a rule of proportionality in between tabulated values (6).

\section{Results}

Age and body weight. The male rats examined in the present study were $14.7 \pm 1.0$ weeks old, with a mean body weight of $441 \pm 17 \mathrm{~g}$ ( $\mathrm{n}=18$ in both cases). Despite a somewhat higher age (22.0 \pm 0.4 weeks), the female rats only weighed $333 \pm 19 \mathrm{~g}$ $(\mathrm{n}=5$ in both cases).

Plasma lipids. The total fatty acid content and pattern of plasma phospholipids, triglycerides, diglycerides and unesterified fatty acids in the $\omega 3$-depleted rats were measured in eighteen male $\omega 3$-depleted rats, which were injected or not 60 min before sacrifice with either the MCT:OO emulsion (OO rats) or MCT:FO emulsion (FO rats).

Plasma phospholipids. In the $\mathrm{OO}$ and FO rats, the plasma concentration of phospholipids, expressed in terms of their total fatty acid content, was higher $(\mathrm{p}<0.01)$ than in the uninjected $\omega 3$-depleted rats (Table II). It failed to differ significantly $(\mathrm{p}>0.2)$ in $\mathrm{OO}$ and $\mathrm{FO}$ rats, with an overall mean value of $1.43 \pm 0.07 \mathrm{mg} / \mathrm{ml}(\mathrm{n}=12)$. As judged from the latter value and that recorded in the uninjected rats, the increment in plasma phospholipid concentration attributable to the prior injection of a lipid emulsion averaged $0.40 \pm 0.11 \mathrm{mg} / \mathrm{ml}$ (d.f. $=16 ; \mathrm{p}<0.005)$. Taking into account the phospholipid content of each lipid emulsion (Table I), the apparent 
Table II. Plasma phospholipid fatty acid content and profile.

\begin{tabular}{|c|c|c|c|}
\hline Rats & NI & $\mathrm{OO}$ & FO \\
\hline Total $(\mu \mathrm{g} / \mathrm{ml})$ & $1032 \pm 43(6)$ & $1340 \pm 75(6)$ & $1518 \pm 118(6)$ \\
\hline $\mathrm{C} 14: 0(\%)$ & $0.3 \pm 0.0(6)$ & $0.3 \pm 0.0(6)$ & $0.2 \pm 0.0(6)$ \\
\hline $\mathrm{C} 16: 0(\%)$ & $21.0 \pm 0.5(6)$ & $23.6 \pm 0.3(6)$ & $22.2 \pm 0.8(6)$ \\
\hline 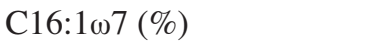 & $1.0 \pm 0.3(6)$ & $0.9 \pm 0.1(6)$ & $0.7 \pm 0.2(6)$ \\
\hline $\mathrm{C} 16: 1 \omega 7 / \mathrm{C} 16: 0\left(\mathrm{x} 10^{3}\right)$ & $33.9 \pm 1.4(5)$ & $35.2 \pm 2.0(6)$ & $34.7 \pm 4.8(5)$ \\
\hline $\mathrm{C} 18: 0(\%)$ & $19.2 \pm 0.8(6)$ & $16.8 \pm 0.3(6)$ & $15.4 \pm 0.8(6)$ \\
\hline 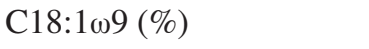 & $4.1 \pm 0.5(6)$ & $8.8 \pm 0.3(6)$ & $8.6 \pm 0.3(6)$ \\
\hline 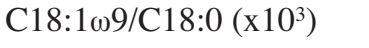 & $211 \pm 37(6)$ & $523 \pm 23(6)$ & $570 \pm 35(6)$ \\
\hline 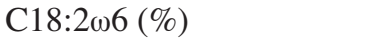 & $19.9 \pm 1.0(6)$ & $17.5 \pm 0.4(6)$ & $19.4 \pm 0.6(6)$ \\
\hline C18:3w6 (\%) & $0.3 \pm 0.2(6)$ & $0.1 \pm 0.0(6)$ & $0.1 \pm 0.0(6)$ \\
\hline C20:0 (\%) & $0.2 \pm 0.0(6)$ & $0.2 \pm 0.0(6)$ & $0.2 \pm 0.0(6)$ \\
\hline 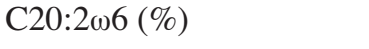 & $0.3 \pm 0.0(6)$ & $0.3 \pm 0.0(6)$ & $0.3 \pm 0.1(6)$ \\
\hline $\mathrm{C} 20: 3 \omega 6(\%)$ & $0.3 \pm 0.3(6)$ & $0.1 \pm 0.1(6)$ & $0.2 \pm 0.1(6)$ \\
\hline $\mathrm{C} 22: 0(\%)$ & $0.5 \pm 0.0(6)$ & $0.4 \pm 0.0(6)$ & $0.3 \pm 0.1(6)$ \\
\hline 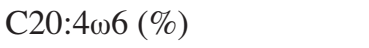 & $30.5 \pm 1.7(6)$ & $27.6 \pm 0.5(6)$ & $28.3 \pm 1.7(6)$ \\
\hline $\mathrm{C} 20: 4 \omega 6 / \mathrm{C} 18: 2 \omega 6$ & $1.57 \pm 0.15(6)$ & $1.58 \pm 0.06(6)$ & $1.48 \pm 0.13(6)$ \\
\hline $\mathrm{C} 20: 5 \omega 3(\%)$ & $0.0 \pm 0.0(6)$ & $0.0 \pm 0.0(6)$ & $0.1 \pm 0.0(6)$ \\
\hline $\mathrm{C} 24: 0(\%)$ & $1.0 \pm 0.0(6)$ & $0.9 \pm 0.0(6)$ & $0.7 \pm 0.2(6)$ \\
\hline $\mathrm{C} 22: 4 \omega 6(\%)$ & $0.6 \pm 0.0(6)$ & $0.7 \pm 0.0(6)$ & $0.6 \pm 0.1(6)$ \\
\hline $\mathrm{C} 22: 4 \omega 6 / \mathrm{C} 20: 4 \omega 6\left(\mathrm{x} 10^{3}\right)$ & $20.4 \pm 1.2(6)$ & $26.7 \pm 0.8(6)$ & $24.2 \pm 1.9(5)$ \\
\hline $\mathrm{C} 22: 5 \omega 3(\%)$ & $0.2 \pm 0.0(6)$ & $0.3 \pm 0.0(6)$ & $0.3 \pm 0.1(6)$ \\
\hline C22:6w3 (\%) & $0.4 \pm 10 .(6)$ & $1.3 \pm 0.1(6)$ & $1.0 \pm 0.2(6)$ \\
\hline $\mathrm{C} 22: 6 \omega 3 / \mathrm{C} 20: 5 \omega 3$ & N.D. & N.D. & $8.12 \pm 0.48(5)$ \\
\hline $\mathrm{C} 22: 6 \omega 3 / \mathrm{C} 22: 5 \omega 3$ & $1.88 \pm 0.06(6)$ & $4.37 \pm 0.23(6)$ & $4.02 \pm 0.35(5)$ \\
\hline
\end{tabular}

N.D., not determined.

distribution space of the injected phospholipids, as assessed 60 min after their intravenous administration, was not significantly different $(\mathrm{p}>0.4)$ in the $\mathrm{OO}$ rats $(87.4 \pm 18.9 \mu \mathrm{l} / \mathrm{g})$ and $\mathrm{FO}$ rats $(66.9 \pm 19.3 \mu \mathrm{l} / \mathrm{g})$, with an overall mean value of $77.2 \pm 13.2 \mu 1$ per $\mathrm{g}$ body weight $(\mathrm{n}=12)$, not vastly different from the plasma volume (Table III).

Likewise, the apparent distribution space of phospholipidassociated $\mathrm{C} 18: 1 \omega 9$ was not significantly different $(\mathrm{p}>0.25)$ in $\mathrm{OO}$ and $\mathrm{FO}$ rats, with an overall mean value of $66.2 \pm 4.8 \mu \mathrm{l} / \mathrm{g}$ $(n=12)$. It represented $98.8 \pm 11.2 \%(n=12 ; p>0.9)$ of the paired apparent distribution space of phospholipids (Table III).

The fatty acid pattern of plasma phospholipids also differed in the three groups of 13 -depleted rats in the two following major respects. First, whilst no C8:0 or C10:0 was detected in any of the uninjected animals, small amounts of these middle-chain fatty acids were not uncommonly found in the other rats. When present, the phospholipid content of C8:0 and C10:0 averaged respectively $2.5 \pm 0.4$ and $2.1 \pm 0.2 \mu \mathrm{g} / \mathrm{ml}$ in the $\mathrm{OO}$ rats $(\mathrm{n}=4)$, and $3.1 \pm 0.3$ and $2.9 \pm 0.1 \mu \mathrm{g} / \mathrm{ml}(\mathrm{n}=3)$ in the $\mathrm{FO}$ rats. The $\mathrm{C} 8: 0 / \mathrm{C} 10: 0$ ratio failed to differ significantly $(\mathrm{p}>0.4)$ in $\mathrm{OO}$ and $\mathrm{FO}$ rats, with an overall mean value of $1.16 \pm 0.06(n=7)$.

Second, whilst no C20:5 03 could be detected in the plasma phospholipids of uninjected rats or those injected with the control MCT:OO emulsion, the C20:5w3 content of rats injected with the MCT:FO emulsion averaged $1.8 \pm 0.4 \mu \mathrm{g} / \mathrm{ml}$ $(n=6)$. The weight percentages of $\mathrm{C} 22: 5 \omega 3$ and $\mathrm{C} 22: 6 \omega 3$ were also higher in the latter rats than in the uninjected animals $(p<0.025)$. However, such percentages were virtually identical in the $\mathrm{OO}$ and FO rats (Table II). The latter situation may be accounted, in part at least, by the two following facts. The weight percentage of these two fatty acids, especially that of C22:6w3, were higher in the injected phospholipids than in the plasma phospholipids of uninjected $\omega 3$-depleted rats. For instance, the weight percentage of $\mathrm{C} 22: 6 \omega 3$ in the phospholipids of the MCT:OO and MCT:FO emulsion (3.7 and $7.8 \%$ ) were 8-18 times higher than that of endogenous phospholipids in the uninjected rats $(0.44 \pm 0.03 \%$; $n=6)$. The higher weight percentages of $\mathrm{C} 22: 5 \omega 3$ and $\mathrm{C} 22: 6 \omega 3$ in the MCT:FO emulsion, as compared to MCT:OO emulsion, happened to coincide with, and hence may well have been compensated by, a larger apparent distribution space of these phospholipid-associated long-chain polyunsaturated $\omega 3$ fatty acids in the $\mathrm{FO}$ rats, as compared to $\mathrm{OO}$ rats. Taking into account both the amount of $\mathrm{C} 22: 5 \omega 3$ and $\mathrm{C} 22: 6 \omega 3$ present in the phospholipids of the injected lipid emulsions and the concentration of these fatty acids in the plasma phospholipids of uninjected $\omega 3$-depleted rats, the apparent distribution space 


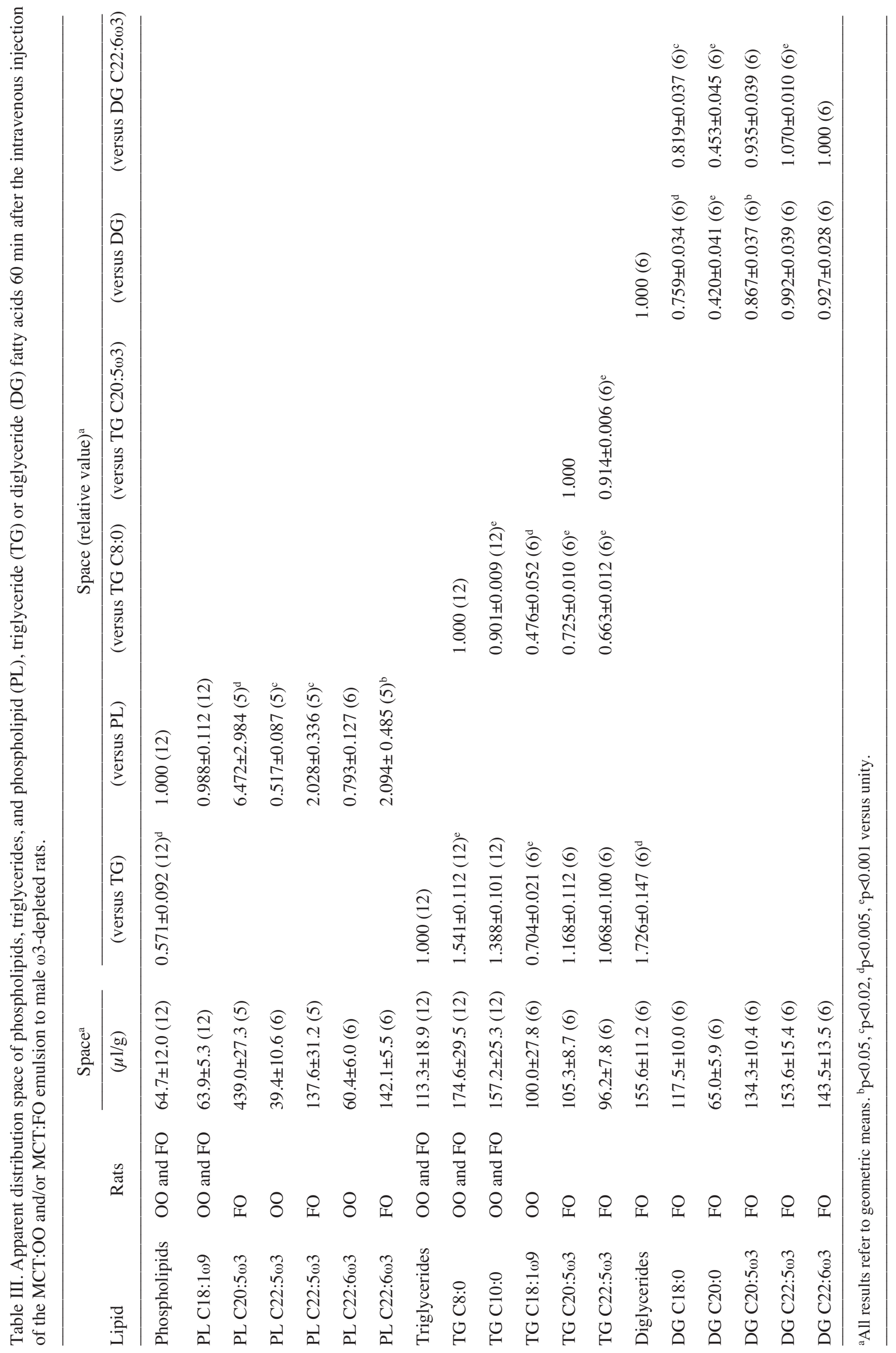



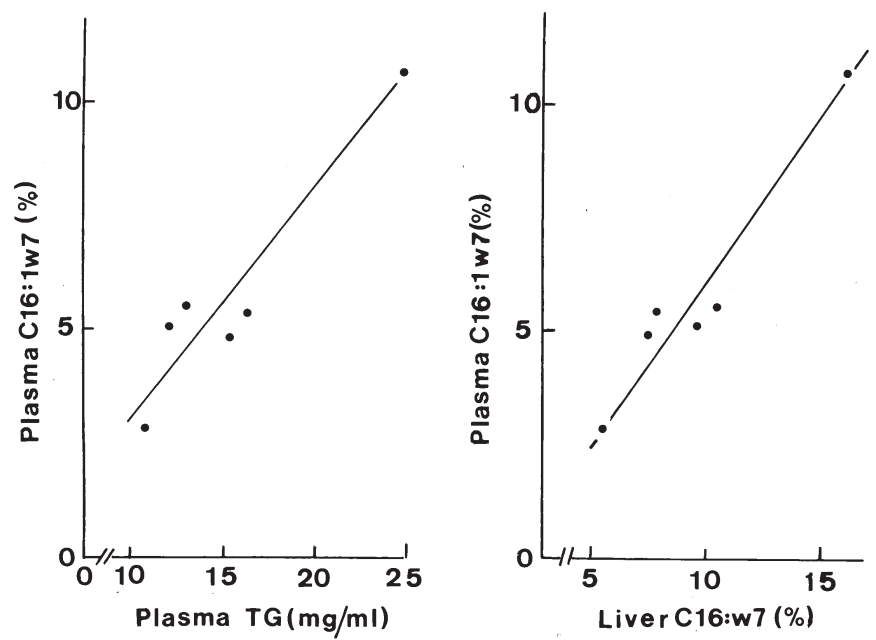

Figure 1. Correlation between the C16:1w7 weight percentage of plasma triglycerides and either the total fatty acid content of such triglycerides (left) or C16:1 107 weight percentage of liver triglycerides in uninjected $\omega 3$-depleted male rats (right). The oblique line represents the correlation line with a slope equal to $\sqrt{\sum y^{2} / \sum x^{2}}$

of both $\omega 3$ fatty acids was 2-3 times higher $(\mathrm{p}<0.01)$ in $\mathrm{FO}$ rats than in $\mathrm{OO}$ rats. It averaged, in the $\mathrm{OO}$ and $\mathrm{FO}$ rats, respectively, $48.0 \pm 15.5(\mathrm{n}=6)$ and $149.3 \pm 24.3(\mathrm{n}=5) \mu 1$ per $\mathrm{g}$ body weight in the case of $\mathrm{C} 22: 5 \omega 3$, and $61.9 \pm 6.3(\mathrm{n}=6)$ and $142.5 \pm 5.4(\mathrm{n}=5) \mu 1$ per $\mathrm{g}$ in the case of $\mathrm{C} 22: 6 \omega 3$. The $\mathrm{C} 22: 5 \omega 3 /$ $\mathrm{C} 22: 6 \omega 3$ individual ratio for the apparent distribution spaces averaged in the $\mathrm{OO}$ and $\mathrm{FO}$ rats, respectively, $65.7 \pm 12.9 \%$ $(n=6)$ and $96.8 \pm 19.1 \%(n=5)$, these two mean values failing to differ significantly from unity $(\mathrm{p} \geq 0.08)$ and from one another $(\mathrm{p}>0.19)$.

Incidentally, the apparent distribution space of phospholipid-associated $\mathrm{C} 20: 5 \omega 3$ in the FO rats $(443 \pm 29 \mu \mathrm{l} / \mathrm{g} ; \mathrm{n}=5)$ was even greater $(\mathrm{p}<0.001)$ than that of $\mathrm{C} 22: 6 \omega 3$, with a mean $\mathrm{C} 20: 5 \omega 3 / \mathrm{C} 22: 6 \omega 3$ paired ratio of $309.0 \pm 15.9 \%(n=5)$.

The contribution of injected phospholipids to the content of circulating lipids in long-chain polyunsaturated $\omega 3$ fatty acids is further documented by the fact that, in both $\mathrm{OO}$ and FO rats, the $\mathrm{C} 22: 6 \omega 3 / \mathrm{C} 22: 5 \omega 3$ ratio was twice higher $(\mathrm{p}<0.001)$ than that found in the plasma phospholipids of uninjected rats, albeit remaining significantly lower $(p<0.001)$ than that found in the corresponding lipid emulsion. Such a contribution of injected phospholipids does not represent, however, the sole factor regulating the weight percentage of long-chain polyunsaturated $\omega 3$ fatty acids in circulating phospholipids. Thus, the $\mathrm{C} 22: 6 \omega 3 / \mathrm{C} 20: 5 \omega 3$ ratio was much higher $(\mathrm{p}<0.001)$ in the plasma phospholipids of FO rats $(8.12 \pm 0.48$; $\mathrm{n}=5$ ) than in the MCT:FO emulsion (1.90).

The $\mathrm{C} 16: 1 \omega 7 / \mathrm{C} 16: 0$ and $\mathrm{C} 18: 1 \omega 9 / \mathrm{C} 18: 0$ ratios in plasma phospholipids provided a further illustration of the impact of injected phospholipids on the fatty acid pattern of plasma phospholipids. In the case of the $\mathrm{C} 16: 1 \omega 7 / \mathrm{C} 16: 0$ ratio, the value found in uninjected rats $\left(33.9 \pm 1.4 \times 10^{-3} ; n=5\right)$ was not vastly different from that found in the lipid emulsions $\left(29.6 \pm 1.4 \times 10^{-3} ; \mathrm{n}=2\right)$, and this coincided with the fact that the results collected in $\mathrm{OO}$ rats $\left(35.2 \pm 2.0 \times 10^{-3} ; \mathrm{n}=6\right)$ and $\mathrm{FO}$ rats $\left(34.7 \pm 4.8 \times 10^{-3} ; n=5\right)$ were comparable to those recorded in the uninjected animals. In the case of the $\mathrm{C} 18: 1 \omega 9 / \mathrm{C} 8: 0$ ratio,
Table IV. Plasma triglyceride fatty acid content and profile.

\begin{tabular}{|c|c|c|c|}
\hline Rats & M-NI & M-OO & $\mathrm{M}-\mathrm{FO}$ \\
\hline Total (mg/ml) & $1.54 \pm 0.20(6)$ & $4.82 \pm 0.81(6)$ & $5.97 \pm 0.74(6)$ \\
\hline $\mathrm{C} 8: 0(\%)$ & $0.0 \pm 0.0(6)$ & $19.9 \pm 2.8(6)$ & $23.2 \pm 1.6(6)$ \\
\hline C10:0 (\%) & $0.0 \pm 0.0(6)$ & $16.8 \pm 2.2(6)$ & $17.3 \pm 1.2(6)$ \\
\hline C12:0 (\%) & $0.0 \pm 0.0(6)$ & $0.0 \pm 0.0(6)$ & $0.0 \pm 0.0(6)$ \\
\hline $\mathrm{C} 14: 0(\%)$ & $1.1 \pm 0.1(6)$ & $0.7 \pm 0.1(6)$ & $0.6 \pm 0.1(6)$ \\
\hline C16:0 (\%) & $26.7 \pm 2.3(6)$ & $14.0 \pm 2.1(6)$ & $11.5 \pm 0.8(6)$ \\
\hline 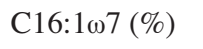 & $5.7 \pm 1.1(6)$ & $2.9 \pm 0.5(6)$ & $2.3 \pm 0.5(6)$ \\
\hline C18:0 (\%) & $2.2 \pm 0.2(6)$ & $1.5 \pm 0.1(6)$ & $1.3 \pm 0.1(6)$ \\
\hline 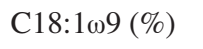 & $25.8 \pm 0.6(6)$ & $23.4 \pm 0.5(6)$ & $12.5 \pm 1.0(6)$ \\
\hline $\mathrm{C} 18: 2 \omega 6(\%)$ & $31.9 \pm 2.9(6)$ & $17.5 \pm 2.4(6)$ & $19.5 \pm 1.2(6)$ \\
\hline C18:3w6 (\%) & $0.5 \pm 0.1(6)$ & $0.2 \pm 0.0(6)$ & $0.2 \pm 0.0(6)$ \\
\hline C20:0 (\%) & $0.2 \pm 0.0(6)$ & $0.1 \pm 0.0(6)$ & $0.1 \pm 0.0(6)$ \\
\hline 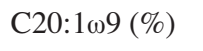 & $0.3 \pm 0.0(6)$ & $0.1 \pm 0.0(6)$ & $0.2 \pm 0.0(6)$ \\
\hline $\mathrm{C} 20: 2 \omega 6(\%)$ & $0.4 \pm 0.1(6)$ & $0.2 \pm 0.0(6)$ & $0.3 \pm 0.0(6)$ \\
\hline C22:0 (\%) & $0.2 \pm 0.0(6)$ & $0.2 \pm 0.0(6)$ & $0.1 \pm 0.0(6)$ \\
\hline 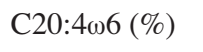 & $3.9 \pm 1.1(6)$ & $1.8 \pm 0.4(6)$ & $2.2 \pm 0.3(6)$ \\
\hline C20:5w3 (\%) & $0.0 \pm 0.0(6)$ & $0.0 \pm 0.0(6)$ & $3.3 \pm 0.2(6)$ \\
\hline 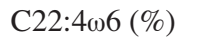 & $1.0 \pm 0.3(6)$ & $0.4 \pm 0.1(6)$ & $0.7 \pm 0.1(6)$ \\
\hline $\mathrm{C} 22: 5 \omega 3(\%)$ & $0.0 \pm 0.0(6)$ & $0.0 \pm 0.0(6)$ & $0.8 \pm 0.0(6)$ \\
\hline C22:6w3 (\%) & $0.0 \pm 0.0(6)$ & $0.0 \pm 0.0(6)$ & $3.6 \pm 0.2(6)$ \\
\hline
\end{tabular}

however, the value found in the uninjected rats $(0.211 \pm 0.037$; $\mathrm{n}=6$ ) was one order of magnitude lower than that prevailing in the lipid emulsions $(2.09 \pm 0.13 ; n=2)$, and this now coincided with the fact that the values recorded in either OO rats $(0.523 \pm 0.023 ; \mathrm{n}=6)$ or FO rats $(0.570 \pm 0.035)$, which were not significantly different from one another $(p>0.25)$, were both much higher $(p<0.001)$ than those found in the uninjected animals.

The ratios between the most abundant long-chain polyunsaturated $\omega 6$ fatty acids present in plasma phospholipids, i.e. the $C 20: 4 \omega 6 / C 18: 2 \omega 6$ and $C 22: 4 \omega 6 / C 20: 4 \omega 6$ ratios, were, as a rule, not significantly different in the uninjected, $\mathrm{OO}$ and FO rats (Table II).

Plasma triglycerides. The total fatty acid of plasma triglyceride was quite variable in the uninjected $\omega 3$-depleted rats ranging between the extreme values of 1.07 and $2.47 \mathrm{mg} / \mathrm{ml}$, with a coefficient of variation (i.e. the $\mathrm{SD} /$ mean value) of $32.6 \%$. In these uninjected rats, there was a highly significant positive correlation between the total fatty acid content of plasma triglycerides and their relative content in $\mathrm{C} 16: 1 \omega 7$ ( $\mathrm{r}=0.943$; $\mathrm{n}=6 ; \mathrm{p}<0.006$ ). As shown in Fig. 1 , in the same uninjected rats, there was also a highly significant positive correlation between the weight percentage of $\mathrm{C} 16: 1 \omega 7$ in plasma and liver triglycerides $(r=0.961 ; n=6 ; p<0.004)$.

The plasma concentration of triglycerides, as judged from their total fatty acid content was much higher $(\mathrm{p} \leq 0.005)$ in the animals injected with either the MCT:OO or MCT:FO emulsion than in the uninjected rats (Table IV). The concentration found in the former animals failed to differ significantly $(\mathrm{p}>0.3)$ in $\mathrm{OO}$ and $\mathrm{FO}$ rats, with an overall mean value of 
$5.39 \pm 0.55 \mathrm{mg} / \mathrm{ml}(\mathrm{n}=12)$. As judged from the difference between the plasma concentration of triglycerides in the animals injected with a lipid emulsion and the mean value found in uninjected rats, the apparent distribution space of the injected triglycerides, $60 \mathrm{~min}$ after their intravenous administration, averaged $135 \pm 28 \mu \mathrm{l} / \mathrm{g}$ body weight $(\mathrm{n}=12)$. It failed to differ significantly ( $\mathrm{p}>0.1)$ in $\mathrm{OO}$ rats $(176 \pm 52 \mu \mathrm{l} / \mathrm{g}$; $\mathrm{n}=6)$ and FO rats $(94 \pm 12 \mu \mathrm{l} / \mathrm{g} ; \mathrm{n}=6)$. The trend towards a lower mean value in the FO rats, as compared to OO rats, was reminiscent of the situation already mentioned above concerning the apparent distribution space of injected phospholipids. As a matter of fact, there was a significant correlation $(\mathrm{p}<0.05)$ between the individual logarithmic values for the apparent distribution spaces of injected phospholipids and triglycerides, with a triglyceride/phospholipid ratio averaging (geometric mean) $1.75 \pm 0.28(n=12 ; p<0.006$ versus unity). In this respect, there was no significant difference ( $\mathrm{p}>0.7$ ) between $\mathrm{OO}$ and $\mathrm{FO}$ rats.

The fatty acid pattern of plasma triglycerides also differed in the three groups of rats under consideration (Table IV). First, whilst no C8:0 or C10:0 was detected in the plasma triglycerides of uninjected $\omega 3$-depleted rats, these two fatty acids were among the most abundant ones in the triglycerides of $\mathrm{OO}$ and FO rats. Their weight percentages failed to differ significantly in the latter two groups of rats, with overall mean values of $21.5 \pm 1.6$ and $17.0 \pm 1.2 \%(\mathrm{n}=12$ in both cases) for C8:0 and C10:0, respectively. The $\mathrm{C} 8: 0 / \mathrm{C} 10: 0$ ratio was significantly higher $(\mathrm{p}<0.001)$, however, in the FO rats $(1.342 \pm 0.006 ; n=6)$ than in the OO rats $(1.184 \pm 0.021 ; n=6)$, both values being significantly lower $(\mathrm{p}<0.001)$ than that prevailing in the triglycerides of the corresponding lipid emulsions. When compared to the $\mathrm{C} 8: 0 / \mathrm{C} 10: 0$ ratio in the corresponding lipid emulsion, that found in the plasma triglycerides of the $\mathrm{OO}$ and FO rats represented, respectively, $88.7 \pm 1.6$ and $91.2 \pm 0.4 \%$ ( $n=6$ in both cases). The latter two percentages now failed to differ significantly from one another ( $p>0.15)$, yielding an overall mean value of $89.9 \pm 0.9 \%(n=12)$ significantly lower $(\mathrm{p}<0.001)$ than unity.

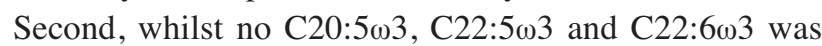
detected in the plasma triglycerides of any uninjected or $\mathrm{OO}$ rat, these long-chain polyunsaturated $\omega 3$ fatty acids accounted,

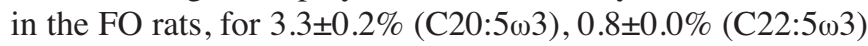
and $3.6 \pm 0.2 \%(\mathrm{C} 22: 6 \mathrm{\omega} 3)$ of the total fatty acid content of plasma triglycerides. Minor amounts of $\mathrm{C} 18: 3 \omega 3$ were also found in the plasma triglycerides of FO rats. Their fractional weight contribution did not exceed $1.12 \pm 0.02 \%$ o $(n=6)$. Nevertheless, the latter value exceeded $(\mathrm{p}<0.001)$ that recorded in either uninjected $\omega 3$-depleted rats, in which no $\mathrm{C} 18: 3 \omega 3$ was detected, or $\mathrm{OO}$ rats, in which the $\mathrm{C} 18: 3 \omega 3$ fractional weight contribution only averaged $0.28 \pm 0.13 \%$ o $(n=6)$. The $\mathrm{C} 22: 6 \omega 3 / \mathrm{C} 20: 5 \omega 3$ ratio in the plasma triglycerides of FO rats averaged $1.081 \pm 0.007(n=6)$, in fair agreement with the fact that the triglycerides and diglycerides of the FO emulsion both contained close-to-equal amounts of C20:5 23 and C22:6w3 (Table I).

Third, the weight percentage of several other fatty acids in plasma triglycerides was significantly lower in rats injected with a lipid emulsion than in uninjected animals. Such was the case for $\mathrm{C} 14: 0(\mathrm{p}<0.05), \mathrm{C} 20: 0(\mathrm{p}<0.01), \mathrm{C} 16: 0(\mathrm{p}<0.005)$, $\mathrm{C} 16: 1 \omega 7(\mathrm{p}<0.05), \mathrm{C} 18: 0(\mathrm{p}<0.005)$ and, in FO rats, for
$\mathrm{C} 18: 1 \omega 9(\mathrm{p}<0.001)$. These changes are largely attributable to the high content of such triglycerides in C8:0 and C10:0. For instance, the fact that the C18:1 09 weight percentage of triglycerides was twice lower in FO rats than in uninjected animals contrasts with a higher absolute value $(\mathrm{p}<0.02)$ for this fatty acid in the former rats $(0.75 \pm 0.11 \mathrm{mg} / \mathrm{ml} ; \mathrm{n}=6)$ than in the latter animals $(0.40 \pm 0.06 \mathrm{mg} / \mathrm{ml} ; \mathrm{n}=6)$. In this case, however, the weight percentage of $\mathrm{C} 18: 1 \omega 9$ in plasma triglycerides was twice higher in $\mathrm{OO}$ rats than in $\mathrm{FO}$ rats and, as such, became comparable to that found in uninjected rats. The latter difference between $\mathrm{OO}$ and FO rats is obviously attributable to the much higher content of $\mathrm{C} 18: 1 \omega 9$ in the triglycerides of the MCT:OO emulsion, as compared to MCT:FO emulsion. Indeed, when taking into account both the total fatty acid content of plasma triglycerides and their relative $\mathrm{C} 18: 1 \omega 9$ weight content in uninjected and $\mathrm{OO}$ rats, the increase in the absolute value for the $\mathrm{C} 18: 1 \omega 9$ content in triglycerides yielded, as judged from the amount of C18:1 19 present in the injected triglycerides of the MCT:OO emulsion, an apparent distribution space of $120 \pm 32 \mu \mathrm{l} / \mathrm{g} \quad(\mathrm{n}=6)$, representing $70.4 \pm 2.1 \%$ of the paired value for the apparent distribution space of the total amount of injected triglycerides (Table III).

The finding that the latter percentage was significantly lower than unity $(\mathrm{p}<0.001)$ led us to conduct a comparable calculation for other fatty acids present in relatively high amounts in the injected triglycerides, i.e. C8:0, C10:0, C20:5 33 and $\mathrm{C} 22: 6 \omega 3$ (Table III). The highest value was reached in the case of $\mathrm{C} 8: 0$. That recorded with $\mathrm{C} 10: 0$ represents $90.1 \pm 0.9 \%(n=12)$ of the paired value found in the same animal for C8:0. The apparent distribution spaces of C20:5 13 and $\mathrm{C} 22: 6 \omega 3$ were not significantly different from those found in the same rat for the injected triglyceride, the value recorded for $\mathrm{C} 22: 6 \omega 3$ averaging $91.4 \pm 0.6 \%(n=6)$ of the paired value for $\mathrm{C} 20: 5 \omega 3$.

The internal consistency of these findings was assessed by computing, in each of the twelve $\omega 3$-depleted rats injected with a lipid emulsion, the theoretical distribution space of injected triglycerides by summing the products obtained through multiplication of the apparent distribution space times the fractional contribution (weight percent) in the injected triglycerides for each of the three (C8:0, C10:0 and C18:1 109 in the MCT:OO emulsion) or four (C8:0, C10:0, C20:5w3 and C22:6w3 in the MCT:FO emulsion) major fatty acids present in these injected triglycerides. Such a computation yielded a geometric mean of $150 \pm 24 \mu \mathrm{l} / \mathrm{g}$ body weight $(\mathrm{n}=12)$, not significantly different $(\mathrm{p}>0.2)$ of the apparent distribution space of the triglycerides as derived from the measurements of the total fatty acid content of plasma triglycerides, i.e. $113 \pm 19 \mu \mathrm{l} / \mathrm{g}$ body weight (Table III).

Like with many other fatty acids, the weight percentage of $\mathrm{C} 20: 1 \omega 9$ in plasma triglycerides was lower $(\mathrm{p}<0.06)$ in OO rats $(1.36 \pm 0.30 \%$; $n=6)$ than in uninjected animals $(2.59 \pm 0.48 \%$; $n=6)$, whereas the mean absolute value of C20:1w9 in plasma triglycerides was higher, albeit not significantly so $(\mathrm{p}>0.18)$ in $\mathrm{OO}$ rats $(5.77 \pm 1.12 \mu \mathrm{g} / \mathrm{ml})$ than in uninjected $\omega 3$-depleted animals $(3.84 \pm 0.73 \mu \mathrm{g} / \mathrm{ml})$. The mean weight percentage of C20:1 $\omega 9(1.94 \pm 0.29 \%$; $n=6)$ and its absolute concentrations $(11.07 \pm 1.50 \mu \mathrm{g} / \mathrm{ml})$ were both higher in FO rats than in $\mathrm{OO}$ rats, but such a difference only 
achieved statistical significance $(\mathrm{p}<0.02)$ in the latter case, i.e. in terms of absolute concentration.

Last, the major difference in the weight percentage of longchain polyunsaturated $\omega 6$ fatty acids in plasma triglycerides again consisted in a decrease attributable to the prior injection of the lipid emulsion. Thus, such a weight percentage was lower in $\mathrm{OO}$ rats than in uninjected animals in the case of $\mathrm{C} 18: 2 \omega 6(\mathrm{p}<0.005), \mathrm{C} 18: 3 \omega 6(\mathrm{p}<0.005), \mathrm{C} 20: 2 \omega 6(\mathrm{p}<0.02)$, $\mathrm{C} 20: 4 \omega 6(\mathrm{p}<0.09)$ and $\mathrm{C} 22: 4 \omega 6(\mathrm{p}<0.13)$. The mean value was also lower in the FO rats than in the uninjected animals in the case of $\mathrm{C} 18: 2 \omega 6(\mathrm{p}<0.005), \mathrm{C} 18: 3 \omega 6(\mathrm{p}<0.005)$, $\mathrm{C} 20: 2 \omega 6(\mathrm{p}<0.07), \mathrm{C} 20: 4 \omega 6(\mathrm{p}<0.15)$ and $\mathrm{C} 22: 4 \omega 6(\mathrm{p}<0.11)$. The finding that such decreases failed, both in the OO and FO rats, to achieve statistical significance in the case of C20:4 06 and C22:4 $\omega 6$, can be accounted for by the observation, that in the uninjected rats, the $C 20: 4 \omega 6$ and $C 22: 4 \omega 6$ weight percentages were quite variable, with variation coefficient of

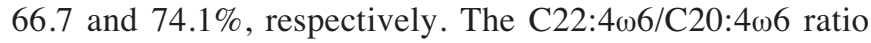
$(0.233 \pm 0.019)$, however, was less variable with a variation coefficient of only $19.6 \%$. A comparable situation prevailed in the $\mathrm{OO}$ rats. In these rats the $\mathrm{C} 22: 4 \omega 6 / \mathrm{C} 20: 4 \omega 6$ ratio in plasma triglycerides $(0.245 \pm 0.007)$ was also comparable $(\mathrm{p}>0.55)$ to that found in the uninjected animals, this coinciding with the fact that the triglycerides of the MCT:OO emulsion were

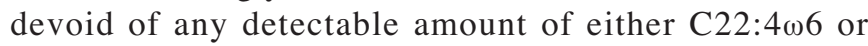
$\mathrm{C} 20: 4 \omega 6$. In the plasma triglycerides of FO rats, however, the

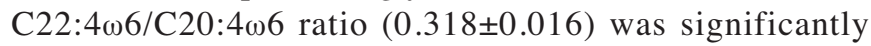
higher $(\mathrm{p}<0.01)$ than in the uninjected animals or OO rats, this coinciding with a $\mathrm{C} 22: 4 \omega 6 / \mathrm{C} 20: 4 \omega 6$ ratio in the triglycerides of the MCT:FO emulsion (0.798) more than thrice higher than in the plasma triglycerides of uninjected rats.

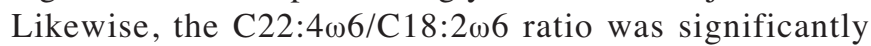
higher $(\mathrm{p}<0.025)$ in the plasma triglycerides of FO rats $(3.56 \pm 0.25 \%)$ than in those of OO rats $(2.45 \pm 0.33 \%)$, this coinciding with a much higher $\mathrm{C} 22: 4 \omega 6 / \mathrm{C} 18: 2 \omega 6$ ratio in the triglycerides of the MCT:FO emulsions (1.80), but not MCT:OO emulsion (0.0), than in the plasma triglycerides of uninjected animals. Inversely, in those cases where the triglycerides of the lipid emulsion contained either no detectable amount of a given fatty acid (e.g. in the case of $\mathrm{C} 18: 3 \omega 6)$ or a weight percentage for a given fatty acid negligible relative to that found in the plasma triglycerides of uninjected rats (e.g. in the case of $\mathrm{C} 18: 2 \omega 6$ ), the results recorded in the plasma triglycerides of $\mathrm{OO}$ and $\mathrm{FO}$ rats failed to differ significantly from one another. The relevance of these findings to the interpretation of liver data should not be ignored.

Plasma diglycerides. The plasma concentration of diglycerides, expressed as their fatty acid content, was higher $(\mathrm{p}<0.001)$ in the animals injected with either the MCT:OO or MCT:FO emulsion than in the uninjected rats (Table V). The increment in such a concentration above the basal value found in the latter rats was higher $(\mathrm{p}<0.001)$ in the FO rats than in the OO rats, being commensurate with the vastly different concentration of diglycerides in these two emulsions (Table I). In the FO rats, this increment yielded an apparent distribution space averaging $158 \pm 12 \mu \mathrm{l} / \mathrm{g}$ body weight $(\mathrm{n}=6)$. Such a space was about twice higher $(\mathrm{p}<0.005)$ than that found in the same rats in the case of phospholipids $(67 \pm 19 \mu \mathrm{l} / \mathrm{g}$ body
Table V. Plasma diglyceride fatty acid content and profile.

\begin{tabular}{|c|c|c|c|}
\hline Rats & M-NI & M-OO & $\mathrm{M}-\mathrm{FO}$ \\
\hline Total $(\mu \mathrm{g} / \mathrm{ml})$ & $11.2 \pm 1.5(6)$ & $57.8 \pm 6.8(6)$ & $258.6 \pm 32.9(6)$ \\
\hline C8:0 (\%) & $0.0 \pm 0.0(6)$ & $3.6 \pm 1.2(6)$ & $0.8 \pm 0.3(6)$ \\
\hline C10:0 (\%) & $0.0 \pm 0.0(6)$ & $6.1 \pm 2.1(6)$ & $1.4 \pm 0.4(6)$ \\
\hline C16:0 (\%) & $23.0 \pm 1.9(6)$ & $13.1 \pm 1.1(6)$ & $4.2 \pm 0.3(6)$ \\
\hline 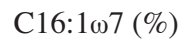 & $1.8 \pm 1.8(6)$ & $3.3 \pm 0.7(6)$ & $1.3 \pm 0.2(6)$ \\
\hline C18:0 (\%) & $0.0 \pm 0.0$ & $3.7 \pm 0.3(6)$ & $2.2 \pm 0.1(6)$ \\
\hline 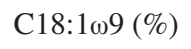 & $31.6 \pm 1.1(6)$ & $34.8 \pm 0.8(6)$ & $7.8 \pm 0.6(6)$ \\
\hline $\mathrm{C} 18: 2 \omega 6(\%)$ & $43.6 \pm 3.9(6)$ & $31.1 \pm 2.2(6)$ & $8.8 \pm 0.9(6)$ \\
\hline C20:0 (\%) & $0.0 \pm 0.0(8)$ & $0.8 \pm 0.4(6)$ & $0.9 \pm 0.1(6)$ \\
\hline 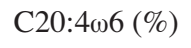 & $0.0 \pm 0.0(6)$ & $0.0 \pm 0.0(6)$ & $3.5 \pm 0.1(6)$ \\
\hline C20:5w3 (\%) & $0.0 \pm 0.0(6)$ & $0.0 \pm 0.0(6)$ & $31.5 \pm 0.9(6)$ \\
\hline 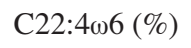 & $0.0 \pm 0.0(6)$ & $0.0 \pm 0.0(6)$ & $1.8 \pm 0.0(6)$ \\
\hline $\mathrm{C} 22: 5 \omega 3(\%)$ & $0.0 \pm 0.0(6)$ & $0.0 \pm 0.0(6)$ & $5.2 \pm 0.2(6)$ \\
\hline $\mathrm{C} 22: 6 \omega 3(\%)$ & $0.0 \pm 0.0(6)$ & $0.0 \pm 0.0(6)$ & $29.5 \pm 0.9(6)$ \\
\hline
\end{tabular}

weight). Actually, the paired diglyceride/phospholipid ratio for their apparent distribution spaces averaged (geometric mean) $2.22 \pm 0.66(n=6 ; p<0.05$ versus unity).

In the FO-rats, the apparent distribution space of diglyceride-associated $\mathrm{C} 20: 5 \omega 3, \mathrm{C} 22: 5 \omega 3$ and $\mathrm{C} 22: 6 \omega 3$ amounted, respectively, to $136.3 \pm 10.6,157.9 \pm 18.2$ and $147.0 \pm 15.7 \mu \mathrm{l} / \mathrm{g}$ ( $\mathrm{n}=6$ in all cases), yielding $\mathrm{C} 20: 5 \omega 3 / \mathrm{C} 22: 6 \omega 3$ and $\mathrm{C} 22: 5 \omega 3 / \mathrm{C} 22: 6 \omega 3$ paired ratios of $93.5 \pm 3.9 \% \quad(n=6$; $\mathrm{p}>0.17$ versus unity) and $107.6 \pm 1.0 \%(\mathrm{n}=6 ; \mathrm{p}<0.001$ versus unity), respectively. Such values were higher than those found in the case of diglyceride-associated C18:0 $(119.9 \pm 11.9 \mu \mathrm{g} / \mathrm{g}$; $\mathrm{n}=6)$ or $\mathrm{C} 20: 0(66.4 \pm 6.0 \mu \mathrm{g} / \mathrm{g} ; \mathrm{n}=6)$, which yielded $\mathrm{C} 18: 0 /$ $\mathrm{C} 22: 6 \omega 3$ and $\mathrm{C} 20: 0 / \mathrm{C} 22: 6 \omega 3$ paired ratios of $81.9 \pm 3.7 \%$ $(n=6 ; p<0.01$ versus unity) and $66.4 \pm 6.0 \%(n=6 ; p<0.001$ versus unity), respectively. Thus, the apparent distribution space of diglyceride-associated long-chain polyunsaturated $\omega 3$ fatty acids was close to that found for the bulk of diglycerides $(155.6 \pm 11.6 \mu \mathrm{l} / \mathrm{g} ; \mathrm{n}=6)$, the latter value being itself significantly higher than that found for the bulk of triglycerides (Table III).

In the uninjected rats, the sole fatty acids consistently identified in the plasma diglycerides were C16:0, C18:1w9 and $\mathrm{C} 18: 2 \omega 6$. Their weight percentage averaged $23.0 \pm 1.9$ for

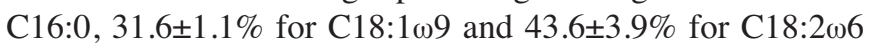
$(\mathrm{n}=6$ in all cases). A vastly different fatty acid pattern was observed in the plasma diglycerides of rats injected with a lipid emulsion.

First, in the latter rats, sizeable amounts of C8:0 and C10:0 were not uncommonly found in plasma diglycerides. Thus, when detected, the weight percent of C8:0 and C10:0 averaged, respectively, $5.3 \pm 0.4$ and $9.2 \pm 1.1 \%(n=4)$ in the OO rats, as compared to only $1.1 \pm 0.1(n=4)$ and $1.7 \pm 0.3$ $(\mathrm{n}=5) \%$ in the FO rats. Although these values, at variance from those listed in Table $\mathrm{V}$, do not include the rats in which these medium-chain fatty acids remained below the limit of detection, they were much lower than those recorded in the diglycerides of either the MCT:OO emulsion for C8:0 (28.2\%) and $\mathrm{C} 10: 0(30.8 \%)$ or the MCT:FO emulsion for C8:0 
Table VI. Plasma unesterified fatty acid concentration.

\begin{tabular}{lccc}
\hline Rats & M-NI & M-OO & M-FO \\
\hline Total $(\mu \mathrm{g} / \mathrm{ml})$ & $32.6 \pm 1.6(6)$ & $99.0 \pm 23.3(6)$ & $132.0 \pm 28.8(6)$ \\
C8:0 $(\mu \mathrm{g} / \mathrm{ml})$ & - & $15.9 \pm 4.2(6)$ & $31.4 \pm 13.0(6)$ \\
C10:0 $(\mu \mathrm{g} / \mathrm{ml})$ & - & $18.1 \pm 6.5(6)$ & $25.1 \pm 9.0(6)$ \\
$\mathrm{C} 16: 0(\mu \mathrm{g} / \mathrm{ml})$ & $10.0 \pm 0.4(6)$ & $18.6 \pm 2.8(6)$ & $17.9 \pm 2.2(6)$ \\
$\mathrm{C} 16: 1 \omega 7(\mu \mathrm{g} / \mathrm{ml})$ & $1.6 \pm 0.4(6)$ & $2.3 \pm 0.6(6)$ & $2.4 \pm 0.5(6)$ \\
$\mathrm{C} 18: 0(\mu \mathrm{g} / \mathrm{ml})$ & $2.5 \pm 0.2(6)$ & $4.5 \pm 0.4(6)$ & $5.1 \pm 0.4(6)$ \\
$\mathrm{C} 18: 1 \omega 9(\mu \mathrm{g} / \mathrm{ml})$ & $7.4 \pm 0.3(6)$ & $19.7 \pm 4.2(6)$ & $12.0 \pm 1.3(6)$ \\
$\mathrm{C} 18: 2 \omega 6(\mu \mathrm{g} / \mathrm{ml})$ & $10.7 \pm 0.9(6)$ & $19.7 \pm 4.8(6)$ & $18.0 \pm 1.8(6)$ \\
$\mathrm{C} 20: 4 \omega 6(\mu \mathrm{g} / \mathrm{ml})$ & - & - & $4.3 \pm 0.3(6)$ \\
$\mathrm{C} 20: 5 \omega 3(\mu \mathrm{g} / \mathrm{ml})$ & - & - & $5.2 \pm 0.7(6)$ \\
$\mathrm{C} 22: 5 \omega 3(\mu \mathrm{g} / \mathrm{ml})$ & - & - & $2.4 \pm 0.6(6)$ \\
$\mathrm{C} 22: 6 \omega 3(\mu \mathrm{g} / \mathrm{ml})$ & - & - & $7.3 \pm 1.1(6)$ \\
\hline
\end{tabular}

(12.8\%) and C10:0 (9.5\%). The absolute amounts of C8:0 and C10:0 in the diglycerides failed to differ in the $\mathrm{OO}$ and FO rats, however, averaging, respectively, when detected, $3.56 \pm 0.35$ and $6.19 \pm 0.74 \mu \mathrm{g} / \mathrm{ml}$ in the former animals $(\mathrm{n}=4)$, as compared to $3.28 \pm 0.58(\mathrm{n}=4)$ and $4.80 \pm 1.15(\mathrm{n}=5) \mu \mathrm{g} / \mathrm{ml}$ in the latter ones. The $\mathrm{C} 8: 0 / \mathrm{C} 10: 0$ ratio was virtually identical in the $\mathrm{OO}$ rats $(0.59 \pm 0.04 ; \mathrm{n}=4)$ and $\mathrm{FO}$ rats $(0.61 \pm 0.05 ; \mathrm{n}=4)$ and lower than that prevailing in the diglycerides of either the MCT:OO (0.95) or MCT:FO (1.35) emulsion.

Second, whilst in $\mathrm{OO}$ rats, alike in uninjected animals, the plasma diglycerides contained no other long-chain polyunusaturated $\omega 6$ fatty acids than $\mathrm{C} 18: 2 \omega 6$, sizeable amounts of

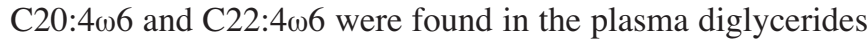
of FO rats. Their weight percentages amounted to $3.5 \pm 0.1 \%$ for $\mathrm{C} 20: 4 \omega 6$ and $1.8 \pm 0.0 \%$ for $\mathrm{C} 22: 4 \omega 6$, with a $\mathrm{C} 22: 4 \omega 6$ / $\mathrm{C} 20: 4 \omega 6$ paired ratio of $0.504 \pm 0.022$ ( $n=6$ in all cases).

Third, in the FO rats, sizeable amounts of C20:5 23 , $\mathrm{C} 22: 5 \omega 3$ and $\mathrm{C} 22: 6 \omega 3$ were invariably found in the plasma diglycerides whilst such was never the case in the other $\omega 3$-depleted rats (Table V).

Except for the consistent presence of detectable amounts of C20:0 in the diglycerides of FO rats and its occasional presence in the diglycerides of $\mathrm{OO}$ rats (Table $\mathrm{V}$ ), other differences in the fatty acid pattern of plasma diglycerides in the three groups of rats under consideration were apparently related to either the vastly different concentrations of diglycerides (e.g. in uninjected rats versus those injected with a lipid emulsion) or to the expression of results in terms of weight percentages rather than absolute values. For instance, such appeared to be the case when comparing the weight percentages of $\mathrm{C} 18: 2 \omega 6$, with the highest value in uninjected rats and animals injected with the MCT:OO emulsion, whilst the absolute values for $\mathrm{C} 18: 2 \omega 6$ ranged from $5.8 \pm 0.3 \mu \mathrm{g} / \mathrm{ml}$ in the uninjected $\omega 3$-depleted rats to $17.5 \pm 1.7$ and $22.0 \pm 2.4 \mu 1 / \mathrm{ml}$ in the $\mathrm{OO}$ and $\mathrm{FO}$ rats, respectively, the latter two mean values failing to differ significantly $(\mathrm{p}>0.1)$ from one another.

Last, and as expected, the fractional contribution of C18:109, when expressed relative to all $\mathrm{C} 16$ and $\mathrm{C} 18$ fatty acids, was higher $(\mathrm{p} \leq 0.005)$ in $\mathrm{OO}$ rats $(40.7 \pm 1.8 \%$; $=6)$ than in either FO rats $(31.9 \pm 0.4 \% ; n=6)$ or uninjected animals $(31.6 \pm 1.1 \% ; \mathrm{n}=6)$.

Plasma unesterified fatty acids. The plasma concentration of unesterified fatty acids averaged, in the $\mathrm{OO}$ and $\mathrm{FO}$ rats respectively, $99.0 \pm 23.3$ and $132.0 \pm 28.8 \mu \mathrm{g} / \mathrm{ml}$, as distinct $(\mathrm{p}<0.02)$ from $32.6 \pm 1.6 \mu \mathrm{g} / \mathrm{ml}$ in uninjected rats $(\mathrm{n}=6$ in all cases). In the latter rats, the sole fatty acids identified yielded mean concentrations of $10.0 \pm 0.4 \mu \mathrm{g} / \mathrm{ml}$ for $\mathrm{C} 16: 0,1.6 \pm 0.4 \mu \mathrm{g} /$ $\mathrm{ml}$ for $\mathrm{C} 16: 1 \omega 7,2.5 \pm 0.2 \mu \mathrm{g} / \mathrm{ml}$ for $\mathrm{C} 18: 0,7.4 \pm 0.3 \mu \mathrm{g} / \mathrm{ml}$ for $\mathrm{C} 18: 1 \omega 9$ and $10.7 \pm 0.9 \mu \mathrm{g} / \mathrm{ml}$ for $\mathrm{C} 18: 2 \omega 6(\mathrm{n}=6$ in all cases).

In several respects, the differences in the fatty acid pattern of unesterified fatty acids in the three groups of rats under consideration were reminiscent of those described above in the case of plasma diglycerides (Table VI). First, in the OO and FO rats, the most abundant unesterified fatty acids were C8:0 and C10:0, which were both undetectable in non-injected animals. The concentration of $\mathrm{C} 8: 0$ and $\mathrm{C} 10: 0$ averaged respectively $15.9 \pm 4.2$ and $18.1 \pm 6.5 \mu \mathrm{g} / \mathrm{ml}$ in $\mathrm{OO}$ rats, and $31.4 \pm 13.0$ and $25.1 \pm 9.0 \mu \mathrm{g} / \mathrm{ml}$ in FO rats, with mean C8:0/C10:0 ratio of $0.97 \pm 0.07$ and $1.14 \pm 0.07$ in $\mathrm{OO}$ and FO rats $(n=6$ in all cases). The latter two ratios were not significantly different from one another, and yielded an overall mean value $1.05 \pm 0.05(\mathrm{n}=12)$, comparable to that recorded in plasma phospholipids and triglycerides of the $\omega 3$-depleted rats injected with a lipid emulsion. Second,

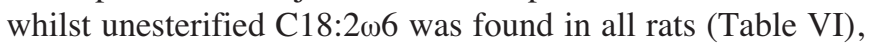
$\mathrm{C} 20: 4 \omega 6$ was only detected in FO rats $(4.3 \pm 0.3 \mu \mathrm{g} / \mathrm{ml} ; \mathrm{n}=6)$ and not so in either uninjected $\omega 3$-depleted rats or the animals injected with the control MCT:OO emulsion. Third, only the FO rats displayed sizeable amounts of plasma unesterified C20:5 $03(5.2 \pm 0.7 \mu \mathrm{g} / \mathrm{ml}), \mathrm{C} 22: 5 \omega 3(2.4 \pm 0.6 \mu \mathrm{g} /$ $\mathrm{ml})$ and $\mathrm{C} 22: 6 \omega 3(7.3 \pm 1.1 \mu \mathrm{g} / \mathrm{ml})$, whilst such was never the case in any of the other twelve $\omega 3$-depleted rats. Last, the weight percentage of $\mathrm{C} 18: 1 \omega 9$ was much higher $(\mathrm{p}<0.001)$ in OO rats $(19.9 \pm 0.9 \% ; n=6)$ than in FO rats $(9.9 \pm 1.0 \% ; n=6)$.

Comparison of plasma and liver values. The comparison between the plasma and liver values was restricted to the weight percentage of fatty acids in the phospholipids and triglycerides of the six male uninjected $\omega 3$-depleted rats for the two following reasons. First, FO and OO rats were not considered because, in these rats, the fatty acid profile of plasma phospholipids and triglycerides was obviously affected by that of the injected corresponding lipids. Second, the exclusion of $\mathrm{FO}$ and $\mathrm{OO}$ rats also avoided the interference of a group effect (e.g. uninjected versus FO rats) when investigating the possible individual correlation between plasma and liver data.

Table VII extends the finding already illustrated in Fig. 1 (right panel) and documenting the existence of a significant positive correlation between the plasma and liver individual values for the weight percentage of $\mathrm{C} 16: 1 \omega 7$ in triglycerides. It indicates that, for ten distinct fatty acids present in phospholipids and for nine distinct fatty acids present in triglycerides, there was always a positive correlation between plasma and liver data. Such a correlation only failed to achieve statistical significance $(\mathrm{p}<0.08)$ in the case of the weight percentage of $\mathrm{C} 18: 2 \omega 6$ and $\mathrm{C} 22: 4 \omega 6$ in phospholipids. 
Table VII. Correlation between plasma and liver individual values for the weight percentage of fatty acids in phospholipids and triglycerides of uninjected male $\omega 3$-depleted rats. ${ }^{a}$

\begin{tabular}{|c|c|c|c|c|c|}
\hline Fatty acid & Plasma & Liver & $\mathrm{r}$ & $\mathrm{n}$ & $\mathrm{p}$ \\
\hline \multicolumn{6}{|c|}{ Phospholipids } \\
\hline C16:0 & $21.0 \pm 0.5$ & $19.5 \pm 0.6$ & 0.860 & 6 & $<0.04$ \\
\hline $\mathrm{C} 16: 1 \omega 7$ & $0.99 \pm 0.29$ & $1.59 \pm 0.35$ & 0.993 & 6 & $<0.001$ \\
\hline C18:0 & $19.2 \pm 0.8$ & $19.4 \pm 0.8$ & 0.945 & 6 & $<0.006$ \\
\hline C18:1w9 & $4.10 \pm 0.52$ & $3.89 \pm 0.42$ & 0.953 & 6 & $<0.005$ \\
\hline C18:2w6 & $19.9 \pm 1.0$ & $12.8 \pm 0.8$ & 0.768 & 6 & $<0.08$ \\
\hline $\mathrm{C} 18: 3 \omega 6$ & $0.26 \pm 0.15$ & $0.42 \pm 0.15$ & 0.989 & 6 & $<0.001$ \\
\hline $\mathrm{C} 20: 4 \omega 6$ & $30.5 \pm 1.7$ & $37.3 \pm 1.5$ & 0.950 & 6 & $<0.006$ \\
\hline $\mathrm{C} 22: 4 \omega 6$ & $0.62 \pm 0.39$ & $0.90 \pm 0.31$ & 0.769 & 6 & $<0.08$ \\
\hline $\mathrm{C} 22: 5 \omega 3$ & $0.23 \pm 0.02$ & $0.13 \pm 0.01$ & 0.877 & 5 & $=0.05$ \\
\hline $\mathrm{C} 22: 6 \omega 3$ & $0.44 \pm 0.03$ & $0.83 \pm 0.05$ & 0.888 & 6 & $<0.03$ \\
\hline \multicolumn{6}{|c|}{ Triglycerides } \\
\hline $\mathrm{C} 14: 0$ & $1.12 \pm 0.13$ & $1.68 \pm 0.11$ & 0.935 & 6 & $<0.007$ \\
\hline $\mathrm{C} 16: 0$ & $26.7 \pm 2.3$ & $38.6 \pm 2.6$ & 0.889 & 6 & $<0.03$ \\
\hline 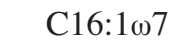 & $5.73 \pm 1.07$ & $9.48 \pm 1.50$ & 0.961 & 6 & $<0.004$ \\
\hline C18:0 & $2.25 \pm 0.16$ & $1.82 \pm 0.17$ & 0.902 & 6 & $<0.02$ \\
\hline 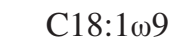 & $25.8 \pm 0.6$ & $29.3 \pm 0.8$ & 0.966 & 6 & $<0.003$ \\
\hline $\mathrm{C} 18: 2 \omega 6$ & $31.9 \pm 2.9$ & $16.7 \pm 4.0$ & 0.963 & 6 & $<0.003$ \\
\hline $\mathrm{C} 18: 3 \omega 6$ & $0.50 \pm 0.05$ & $0.49 \pm 0.05$ & 0.978 & 5 & $<0.005$ \\
\hline C20:4w6 & $3.92 \pm 1.07$ & $1.33 \pm 0.49$ & 0.915 & 6 & $<0.02$ \\
\hline $\mathrm{C} 22: 4 \omega 6$ & $0.85 \pm 0.32$ & $0.30 \pm 0.16$ & 0.924 & 5 & $<0.03$ \\
\hline
\end{tabular}

${ }^{a}$ The correlation coefficient $(r)$ is shown together with the number of individual observations (n) and corresponding probability (p).

In our opinion, it should be emphasized that the correlations listed in Table VII concerned a homogenous group of only six rats all of the same sex, same nutritional state and not vastly different ages. As a matter of fact, in certain cases the coefficients of variation for the individual measurements were quite low, not exceeding, for instance in the case of the C18:1 19 content of triglycerides $6.1 \pm 0.8 \%(n=2)$ in liver and plasma, and yet a significant positive correlations was observed in almost all cases, with a probability $<0.003$ in the just mentioned example of $\mathrm{C} 18: 1 \omega 9$ in triglycerides. Likewise, in the case of the C16:0 content of phospholipids, the coefficient of variation did not exceed $6.6 \pm 0.9 \%(n=2)$ and the probability for the correlation between liver and plasma data was $<0.04$. Moreover, a significant correlation was reached for certain fatty acids which represented only a minor fraction of the total fatty acid content. Such was the case, for instance, with $\mathrm{C} 22: 5 \omega 3$ in phospholipids, the weight percentage of which did not exceed $0.13 \pm 0.01$ and $0.23 \pm 0.02 \%$ in liver and plasma, respectively ( $\mathrm{n}=5$ in both cases). In these respects, the correlation between the $\mathrm{C} 18: 3 \omega 6$ weight percentage in liver and plasma phospholipids was possibly the most impressive. Whilst such a weight percentage did not exceed $0.26 \pm 0.15$ and $0.42 \pm 0.15 \%$ in plasma and liver, respectively, the coefficient of correlation (0.989) derived from six individual rats and, hence, with a degree of freedom of only 4 , yielded a probability well below 0.001 .
It should not be ignored, however, that some of these tight correlations refer to absolute values significantly different in liver and plasma. For instance, the weight percentage of C22:6w3 in phospholipids was twice higher in liver than in plasma, whereas a mirror image prevailed in the case of the weight percentage of $\mathrm{C} 18: 2 \omega 6$ in triglycerides $(\mathrm{p}<0.02$ in these two instances). In a few other cases, however, the absolute values were virtually identical in liver and plasma,

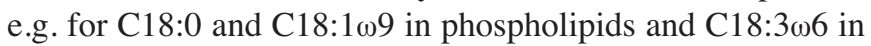
triglycerides, with paired liver/plasma ratio, in these three

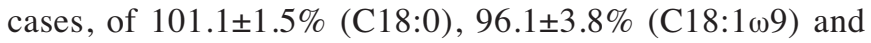
$97.8 \pm 2.0 \%(\mathrm{C} 18: 3 \omega 6)$.

\section{Discussion}

The present study differs from our prior investigations in second generation $\omega 3$-depleted rats in two major respects. First, male and female rats were examined in the course of the same series of experiments, all injected animals being examined $60 \mathrm{~min}$ after the intravenous administration of the lipid emulsion. In prior investigations, male and female rats were examined in separate laboratories under distinct experimental conditions, the male rats being also much older than the female animals (7-9). Moreover, the latter animals were sacrified either 60 or 120 min after intravenous injection of the lipid emulsion. The modality for the intravenous 
administration of the lipid emulsions also differed in the present and former experiments. In this study, anesthetized rats were injected in the saphenous vein, whilst conscious rats were injected in the tail vein in our prior work. Second, the MCT: FO emulsions used in our prior investigations and in the present study were prepared by two distinct companies. Furthermore, the analysis of the results collected in this study includes several variables that were not considered in prior investigations.

The data collected on the plasma of the NI, OO and FO male rats provide several new pieces of information. First, they document that, even in a homogeneous group of only six male $\omega 3$-depleted rats of comparable age, significant correlations are, as a rule, observed between the liver and plasma weight percentages of most phospholipid and triglyceride fatty acids. Hence, measurements made in plasma lipids allow to estimate the fatty acid pattern of the corresponding liver lipids. This indirect approach may be most helpful for further investigations, especially if the same animals are to be examined on successive occasions, e.g. to monitor their response to an increased dietary intake of longchain polyunsaturated $\omega 3$ fatty acids.

Second, they reflect the changes in the acid profile of plasma lipids following the intravenous injection of the MCT:FO and MCT:OO emulsions. As such, they were found essential to establish the link between changes in liver phospholipid and liver triglyceride composition. For instance, they allowed in selected instances, e.g. in the case of the C22:4w6 weight percentage in liver triglycerides, to distinguish between changes attributable to the hepatic uptake of plasma triglycerides and those possibly resulting from the enrichment of liver phospholipids in long-chain polyunsaturated $\omega 3$ fatty acids (10).

Third, they provided information on the fate of the exogenous lipids present in the lipid emulsions and injected intravenously $60 \mathrm{~min}$ before sacrifice. For instance, in the case of phospholipids, the apparent distribution space of both the bulk of injected phospholipids and the phospholipidassociated C18:1 109 suggested that their distribution was possibly restricted to the plasma volume. A different situation prevailed, however, in the case of the phospholipid-associated long-chain polyunsaturated $\omega 3$ fatty acids. In the latter respect, two findings merit to be underlined. First, there were obvious differences in the fate of $\mathrm{C} 20: 5 \omega 3, \mathrm{C} 22: 5 \omega 3$ and C22:6 63 . Pooling together all available and relevant measurements, the apparent distribution space of C22:5 03 and $\mathrm{C} 20: 5 \omega 3$ averaged, respectively, $78.3 \pm 11.4 \%(\mathrm{n}=11)$ and $309.0 \pm 15.9 \%(n=5)$ of the paired value found in the same animal(s) in the case of $\mathrm{C} 22: 6 \omega 3$. Second, when comparing OO rats to $\mathrm{FO}$ rats, it became obvious that the apparent distribution space of both $\mathrm{C} 22: 5 \mathrm{\omega} 3$ and $\mathrm{C} 22: 6 \mathrm{w} 3$ was 2-3 times higher in $\mathrm{FO}$ rats than in $\mathrm{OO}$ rats. This finding is reminiscent of a prior observation indicating that the MCT:OO and MCT:FO emulsions may differ from one another, e.g. in terms of their sensitivity to lipoprotein lipase-catalyzed hydrolysis, subsequent modality for the entry of fatty acids into cells and/or their eventual metabolic fate. The most likely explanation for the difference between $\mathrm{OO}$ and $\mathrm{FO}$ rats, in terms of the fate of phospholipid-associated $\mathrm{C} 22: 5 \omega 3$ and $\mathrm{C} 22: 6 \omega 3$ may indeed well consist in their more rapid clearance from circulation in the latter rats than in the former ones.
Fourth, our data suggest a more rapid clearance from circulation of the diglycerides, as compared to triglycerides, injected in the FO rats. Since the latter difference coincided with a much higher weight percentage of long-chain polyunsaturated $\omega 3$ fatty acids in the diglycerides than in the triglycerides of the MCT:FO emulsion (diglyceride/triglyceride ratio : $5.46 \pm 0.07 ; n=3 ; p<0.001$ ), it may again reflect the more rapid clearance of diglyceride-associated $\omega 3$ fatty acids than that of other diglyceride-associated fatty acids, e.g. C18:1 109 . This proposal is further supported by the three following series of observations. First, the fact that no long-chain polyunsaturated $\omega 3$ fatty acids could be detected in the diglyceride of the MCT:OO emulsion coincided with a lower $(\mathrm{p}<0.005)$ apparent distribution space of such diglycerides in the $\mathrm{OO}$ rats, as compared to FO rats. Despite the fact that the mean increment in the plasma concentration of diglyceride-associated fatty acids above the mean value found in NI rats $(13.9 \pm 1.5 \mu \mathrm{g} /$ $\mathrm{ml}$; $\mathrm{n}=6)$ was $\sim 6$ times lower in OO rats $(42.0 \pm 6.9 \mu \mathrm{g} / \mathrm{ml}$; $\mathrm{n}=6)$ than in FO rats $(243.5 \pm 32.9 \mu \mathrm{g} / \mathrm{ml} ; \mathrm{n}=6)$, an apparent distribution space of such fatty acids could nevertheless be estimated in the former rats. It averaged 80.2 $\pm 15.8 \mu \mathrm{l} / \mathrm{g}(\mathrm{n}=6)$, as distinct $(\mathrm{p}<0.005)$ from 155.6 $\pm 11.2 \mu \mathrm{l} / \mathrm{g}(\mathrm{n}=6)$ in the FO rats. Second, the apparent distribution space of diglycerideassociated $\mathrm{C} 18: 1 \omega 9$, taken as representative of a non- $\omega 3$ fatty acid, was not significantly different $(\mathrm{p}>0.2)$ in $\mathrm{OO}$ rats $(65.6 \pm 11.9 \mu \mathrm{l} / \mathrm{g} ; \mathrm{n}=6)$ and FO rats $(86.2 \pm 9.8 \mu \mathrm{l} / \mathrm{g})$. Moreover, in both types of rats, it was significantly lower $(\mathrm{p}<0.003)$ than the paired apparent distribution space of the total diglyceride-associated fatty acid. Last, in both $\mathrm{OO}$ and FO rats, there was a highly significant correlation between the individual values for the distribution of diglyceride-associated total fatty acids, on one hand, and the individual values for the most abundant long-chain diglyceride-associated fatty acid (i.e. $\mathrm{C} 18: 1 \omega 9$ in the $\mathrm{OO}$ rats and $\mathrm{C} 22: 6 \omega 3$ in the $\mathrm{FO}$ rats) present in the injected diglycerides, on the other hand. The correlation coefficient between these two variables amounted to 0.9759 and 0.9756 in OO and FO rats, respectively ( $n=6$ and $\mathrm{p}<0.001$ in both cases). It cannot be ignored, however, that, in the $\mathrm{OO}$ and $\mathrm{FO}$ rats, circulating diglycerides could conceivably be generated from circulating triglycerides, in a manner comparable to that documented in vitro upon exposure of lipid emulsions to lipoprotein lipase (11).

Fifth, as far as the unesterified fatty acids are concerned, two points merit to be mentioned. First, at variance with a prior study also conducted in second generation $\omega 3$-depleted male rats (9), the mean plasma concentration of individual unesterified fatty acids was never lower in the present animals injected with a lipid emulsion than in the uninjected $\omega 3$-depleted male rats. In this respect, the present findings are nevertheless compatible with an impaired regulatory inhibition of intracellular lipolysis in $\omega 3$-depleted rats. Second, although a contributive role of the injected unesterified fatty acids present in the lipid emulsions to the increase in lipadicemia should not be ignored, it certainly does not represent the sole factor for such an increase. Thus, in the case of C8:0 and C10, such a process would correspond to an apparent distribution space of no more than $17.3 \pm 2.2$ and $12.1 \pm 2.2 \mu \mathrm{l} / \mathrm{g}(\mathrm{n}=12$ in both cases), respectively, with a $\mathrm{C} 8: 0 / \mathrm{C} 10: 0$ paired ratio of $142.3 \pm 6.8 \%(\mathrm{n}=12 ; \mathrm{p}<0.001$ versus unity). Moreover, a sizeable increase in the plasma concentration of certain 
unesterified fatty acids in the $\mathrm{OO}$ and $\mathrm{FO}$ rats, as distinct from NI rats, was observed even when the concerned unesterified fatty acid could not be detected in the lipid emulsion. Such was the case for C16:1 107 , the plasma concentration of which, whenever above the limit of detection, was $0.34 \pm 0.13 \mu \mathrm{g} / \mathrm{ml}$ higher (d.f. $=13 ; \mathrm{p}<0.025$ ) in the rats injected with a lipid emulsion than in the uninjected rats.

Last, the present measurements are relevant to the fate of the injected middle-chain fatty acids C8:0 and C10:0. The C8:0/C10:0 ratio was comparable in the male OO and FO rats, whether in plasma phospholipids, triglycerides, diglycerides and unesterified fatty acids or liver triglycerides. In these rats, it decreased from a mean value of $1.331 \pm 0.083$ $(n=6)$ in the triglycerides, diglycerides and unesterified fatty acids of the MCT:OO and MCT:FO emulsion to $1.263 \pm 0.026$ $(n=12)$ in the plasma triglycerides, $1.156 \pm 0.064(n=7)$ in the plasma phospholipids, $1.055 \pm 0.054(\mathrm{n}=12)$ in the plasma unesterified fatty acids, $0.695 \pm 0.031(\mathrm{n}=12)$ in the liver triglycerides, and $0.597 \pm 0.030(n=8)$ in the plasma diglycerides. These findings can be accounted for by both the higher sensitivity of the ester bond to lipoprotein lipase and greater volatility of the unesterified fatty acid in the case of C8:0, as compared to C10:0 (11).

\section{Acknowledgements}

This study was supported by a grant (3.4574.07) from the Belgian Foundation for Scientific Medical Research. We are grateful to A. Chwalik and A. Dufour for technical assistance, and to C. Demesmaeker and P. Surardt for secretarial help.

\section{References}

1. Carpentier YA and Hacquebard M: Intravenous lipid emulsions to deliver omega 3 fatty acids. Prostaglandins Leukot Essent Fatty Acids 75: 145-148, 2006.
2. Portois L, Deckelbaum RJ, Malaisse WJ and Carpentier YA: Accumulation rapide d'eicosapentaenoate dans les phospholipides cellulaires après injection intraveineuse d'une émulsion d'huile de poisson et de triglycérides à chaîne moyenne à des sujets normaux. Nutr Clin Metabol 18 (Suppl 1): S53, 2004.

3. Oguzhan B, Zhang Y, Louchami K, Courtois P, Portois L, Chardigny JM, Malaisse WJ, Carpentier YA and Sener A: Pancreatic islet function in $\omega 3$ fatty acid-depleted rats. Glucose metabolism and nutrient-stimulated insulin release. Endocrine 29: 457-466, 2006.

4. Richelle M, Carpentier YA and Deckelbaum RJ: Long- and medium-chain triacylglycerols in neutral lipid-exchange processes with human plasma low-density lipoproteins. Biochemistry 33 : 4872-4878, 1984.

5. Leclercq-Meyer V, Malaisse-Lagae F, Coulic V, Akkan AG and Malaisse WJ: Preservation of the anomeric specificity of glucoseinduced insulin release in partially pancreatectomized rats. Diabetologia 35: 505-509, 1992.

6. Document Geigy: Mathématiques et Statistique. Ciba-Geigy SA (ed). Basel, 1973

7. Portois L, Peltier S, Chardigny JM, Sébédio JL, Leverve X, Malaisse WJ and Carpentier YA: Rapid incorporation of longchain polyunsaturated $\omega 3$ fatty acids and lowering of triglycerides in the liver of $\omega 3$-depleted rats injected with a medium-chain triglyceride:fish oil emulsion. Eur J Physiol 450: R11, 2005.

8. Louchami K, Zhang Y, Oguzhan B, Delporte C, Portois L, Carpentier YA, Genten F, Danguy A, Malaisse WJ and Sener A: Rapid changes in liver lipid composition and pancreatic $\mathrm{K}^{+}$ handling and secretory behaviour provoked by the intravenous administration of a medium-chain triglyceride:fish oil emulsion to long-chain polyunsaturated $\omega 3$ fatty acid-depleted rats. Int J Mol Med 18: 1047-1055, 2006.

9. Carpentier YA, Peltier S, Portois L, Chardigny JM, Sébédio JL, Leverve X and Malaisse WJ: Accelerated clearance of plasma triglycerides and free fatty acids in $\omega 3$-depleted rats. Horm Metab Res 39: 295-305, 2007.

10. Carpentier YA, Peltier S, Portois L, Sener A and Malaisse WJ: Rapid lipid enrichment in $\omega 3$ fatty acids: Liver data. Int J Mol Med 21: 367-373, 2008

11. Carpentier YA, Dupont I, Portois L and Malaisse WJ: Preclinical investigations of a medium-chain triglyceride:fish oil emulsion. I. Effects of bovine milk lipoprotein lipase on lipid composition. Int J Mol Med 18: 761-773, 2006. 